\title{
Relaciones entre el Estado español y sus Comunidades Autónomas
}

\section{Relations between the Spanish State and its Autonomous Communities}

\section{Relações entre o Estado espanhol e as suas comunidades autónomas}

\author{
Carmen Belén Guillén Pérez ${ }^{1}$
}

\section{Resumen}

El presente escrito analiza la compleja relación entre la autodeterminación de las Comunidades Autónomas españolas y el Gobierno central, en el marco de un principio de colaboración que resulta al final ser un límite para las partes en distintos ámbitos y en especial en materia tributaria. En análisis de realiza a la luz de la propia Carta política y de los pronunciamientos del tribunal constitucional.

Palabras clave: Descentralización, Competencias estatales, Estado español, Política fiscal, Tributos estatales.

\begin{abstract}
This paper analyzes the complex relationship between the self-determination of the Spanish Autonomous Communities and the central Government, within the framework of a collaboration principle that ultimately results in being a limit for the parties in different fields and especially in tax matters. In the analysis carried out in the light of the Political Charter itself and the pronouncements of the constitutional court.
\end{abstract}

Keywords: Decentralization, State competences, Spanish state, Fiscal policy, State taxes. 


\section{Resumo}

Este artigo analisa a complexa relação entre a autodeterminação das comunidades autônomas espanholas e o governo central, no âmbito de um princípio de colaboração que acaba por ser um limite para as partes em diferentes campos e, especialmente, em matéria tributária. Na análise realizada à luz da própria Carta Política e dos pronunciamentos do Tribunal Constitucional.

Palavras-chave: Descentralização, Competências estatais, Estado espanhol, Política fiscal, Impostos estatais

\section{Introducción}

La Constitución española de 1978 y las sentencias del Tribunal Constitucional configuran la complejidad del Estado autonómico y establecen la necesidad de crear instrumentos jurídicos que ayuden a mejorar las relaciones interterritoriales, lo cual afecta el ejercicio de las competencias de las instancias central y autonómica, exigiendo que se mantenga un principio de colaboración, que se configura como un límite a la independencia de las partes en el ejercicio de sus poderes.

En el artículo 137 y siguientes, la Constitución reconoce la existencia de Comunidades Autónomas como entidades territoriales (provincias limítrofes con características históricas, culturales y económicas comunes; los territorios insulares, y las provincias con entidad regional histórica, susceptibles de acceder a un régimen autonómico de autogobierno). El artículo 131 les otorga autonomía para la gestión de sus intereses. A su vez, el artículo 148 les atribuye un ámbito de competencia específica en relación con las del Estado (artículo 149) y el artículo 150.2 les reconoce la posibilidad de que, por vía de delegación, ejerciten competencias originariamente pertenecientes al Estado.

En la referida solidaridad entre el Estado y las Comunidades Autónomas, los principios de coordinación y cooperación no se pueden desligar de la derogada Ley 30/1992, de Régimen Jurídico de las Administraciones Públicas y Procedimiento Administrativo Común (modificada por Ley 39/2015 de 1 de octubre). En la exposición de motivos de la Ley 30/1992, se cita la necesidad y obligación de cooperación, que debe existir entre las distintas Administraciones, estableciendo esa obligación como un deber, y considerándose la base del modelo de organización territorial, para conseguir el buen funcionamiento del Estado de las Autonomías.

\section{Discusión}

Sin embargo, aceptado el principio y entendiéndose la obligación social o, si se prefiere, moral, la cuestión es determinar cuál es su alcance, puesto que no existe una normativa que sea vinculante, que exija de manera explícita y unilateral su cumplimiento.

El principio de colaboración, aparentemente débil en los cauces de participación en el ámbito político parlamentario general, puede ser uno de los factores que explican las carencias y deficiencias observadas en las relaciones de colaboración, junto al predominio de las relaciones bilaterales, solo relativizada tras los Acuerdos Autonómicos de 1992 y los desarrollos a los que estos han dado lugar. Este principio dispone de un ámbito de aplicación demasiado amplio 
dentro de las competencias distribuidas entre los diferentes entes autonómicos, pudiendo llegar fácilmente a situaciones de conflicto, al facilitar la extralimitación en algunas competencias traspasadas por el Estado a las Comunidades Autónomas, en el ánimo de atender demandas regionales o facilitar el acceso a servicios públicos. Pero, en ocasiones, ocurre otra circunstancia, la de existir duplicidad de competencias que no fueron bien delimitadas.

Lo que, prima facie, podrían considerarse supuestos, en la práctica resultan generalizaciones que, demasiado habitualmente, generan conflictos entre Comunidades y entre estas y el Estado. Sin menoscabo de las competencias asumidas por cada territorio, el único factor limitador parece ser la supremacía estatal que, además, obligue a la colaboración recíproca en cualquier dirección. Una de las funciones que se encomiendan en el citado principio de colaboración, es el establecimiento del deber de auxilio entre las distintas partes del territorio español y del ente central con las regiones que lo integran, lo que supone también la coordinación y cooperación mutua.

No obstante, este tipo de cooperación necesaria debe materializarse, como principio necesario, en todos los acuerdos del Estado y las Comunidades Autónomas. Algunos de los medios de coordinación que se establecieron en los distintos procesos de descentralización administrativa, estaban ya previstos y regulados en el artículo 5 y siguientes de la Ley 30/1992: "las conferencias sectoriales, los convenios de colaboración, los planes y programas conjuntos, aunque también pueden citarse otros como las comisiones bilaterales de cooperación".
En todos los principios y procedimientos, se ha ido reconociendo la indisolubilidad de la unidad de la Nación española y el reconocimiento de la existencia de las autonomías como partes que la forman. Sin embargo, la efectividad de ambos principios debe estar ligada o subordinada al principio de lealtad institucional, criterio rector que ha de facilitar la colaboración y cooperación entre las diferentes Administraciones Públicas. Esto es porque la confluencia de distintas Administraciones sobre un mismo espacio físico, actividad o sector, caracteriza este Estado y su desarrollo.

El tiempo ha demostrado que el Estado dispone de medios necesarios y suficientes para poder proveer o disponer de un sistema eficiente de coordinación con la Comunidades Autónomas, con base en las necesidades que tengan y en las competencias de que dispongan. Sin embargo, existe una serie de mecanismos o procedimientos, que permiten dicha participación de todas y cada una de las entidades territoriales, lo cual genera planteamientos sobre los efectos de esta realidad en el ámbito tributario.

Para poder crear un Estado plenamente descentralizado, donde la autonomía sea completamente real y efectiva y, a la par, se empleen técnicas de colaboración de coordinación y cooperación entre el Estado y las comunidades autónomas y, también indiscutiblemente, entre estas entre sí, debe existir un vínculo al principio de lealtad institucional. Y este no puede considerarse un imperativo solo para el mismo, sino además para el resto de las diferentes Comunidades Autónomas, porque es el propio artículo 156.1 de la Constitución el que determina la autonomía de las comunidades, para poder disponer de 
forma efectiva del reconocimiento de sus competencias, respetando el principio de coordinación con el Estado y, a su vez, el de la solidaridad entre los ciudadanos.

Sin embargo, el artículo 138.2 conecta de manera taxativa el principio de solidaridad con el principio de neutralidad, de manera que el Estado no se identifique con los valores de una determinada religión o ideología, debiendo haber respeto, dentro del límite del orden público, de cualquier concepción por minoritaria que sea, lo que requiere una homogeneidad para el mantenimiento de un orden jurídico duradero, incluso dentro de una sociedad plural. El principio de neutralidad está unido también al principio de territorialidad y, a su vez, al de igualdad, donde se admite la libertad de transitar las personas y los bienes por todo el territorio del Estado, sin que ello implique privilegio o beneficio económico social.

Por tanto, debe de establecerse una relación de plena colaboración entre los distintos entes territoriales, dándose una estrecha vinculación entre todos, y considerándose en todo momento la autonomía de cada una de ellas, sea cual sea la forma de acceso a la autonomía y esto incluso en aspectos impositivos, de ser del caso. Es en el primer artículo de la Ley Orgánica 8/1980, de 22 de septiembre, de Financiación de las Comunidades Autónomas (LOFCA), en la que se reconoce y establece de forma expresa todo lo mencionado.

También habría que reseñar que la diferente forma de haber accedido a la autonomía, no debería en ningún caso dar lugar-o implicar-diferencias económicas o sociales que produjeran un menoscabo de los derechos que le corresponden que, en todo caso, deben ser iguales para los ciudadanos de todas las Comunidades Autónomas.

Por consiguiente, sí hay que decir que, gracias a las diferentes vías establecidas en la Constitución para acceder a la autonomía, al final del proceso, una vez finalizada (en teoría) la incesante dinámica de transferencias de las competencias, se ha dado lugar a un tipo de igualdad similar o con intentos de similitud entre todas las Comunidades Autónomas.

La forma de acceso a la autonomía no permite, en cualquier caso, utilizar uno u otro procedimiento de los establecidos en la Constitución y no determina ninguna calificación de autonomías de primera o de segunda categoría. Eso sería discriminatorio e ilegal, al considerar que según la forma como hayan accedido poseen más o menos privilegios.

El problema, que se reitera, es la atribución de competencias aplicadas de distinta forma a algunas comunidades autónomas, amparándose en sus propios estatutos. Y así, es difícil realizar una labor de colaboración recíproca entre comunidades autónomas que sean muy dispares o diferentes en las competencias básicas que dispongan, dando lugar a un desnivel competencial y ocasionando que las relaciones de colaboración sufran de defectos.

Sin embargo, es un hecho que la forma de acceder (tanto por el artículo 143 como por el artículo 151 de la Constitución) permitió un acceso muy rápido a la asunción de competencias. Eso sí, fuese cual fuese la forma de acceso y una vez alcanzado el mismo 
nivel competencial en la terminación del proceso, las Comunidades se ven obligadas a colaborar con el Estado y a cooperar con otras administraciones regionales que lo necesiten, con mutuo apoyo y sin ningún tipo de obstáculos en las relaciones entre todos.

Por tanto, las Administraciones Central y Autonómicas deben estar obligadas a cumplir con unos mínimos necesarios, esos instrumentos que deben garantizar la armonía (entre pluralidad y unidad) en los procesos de descentralización política y administrativa. Entre esos mínimos, el deber de auxilio y la exigida colaboración, tal como dice la jurisprudencia en mayor o menor intensidad $\mathrm{y}$ con diferente grado de cumplimiento.

Así, las Comunidades Autónomas deben informar al Estado de cualquier situación que les sea exigida dentro de sus competencias y también este debe cooperar y otorgar la información que le requiera la Comunidad Autónoma. Todo ello siempre que no infrinja cualquier normativa al respeto. Entendiendo por información, no solo en sentido estricto, sino también en prestar el apoyo y soporte preciso para que se pueda ejercer las competencias atribuidas o inherentes.

Además de la información, tanto el Estado como las Comunidades Autónomas deben aportar los recursos humanos y materiales que se necesiten para favorecer el desarrollo de la otra Administración.

Pero, ante todo, debe evitarse dar lugar a duplicidades que, además de la competencia, producirán un mayor gasto para ambas, pudiendo sus consecuencias chocar con distintos criterios básicos constitucionales.
Por tanto, sobre la base de esas relaciones ideales que deben existir entre las Administraciones Públicas, sean Estado o Comunidades Autónomas, el principio de coordinación es uno de los ejes básicos que ha de integrar la colaboración. El problema es que, periódica y reiteradamente, se ponen en duda las vías de cooperación existentes, instrumentos habilitados, pero que no logran garantizar los derechos entre las partes.

Otra circunstancia observada es que los distintos procedimientos utilizados para cooperar entre diferentes entes se caracterizan por ser lentos y apenas delimitan el contenido de cómo, por qué y en qué situaciones intervenir y cooperar. Lo cierto es que, para poder mantener el vigente Estado de las Autonomías, sí debe reivindicarse el cumplimiento de aquellos instrumentos que sean necesarios para que sea posible cumplirlo como tal. Los instrumentos a desarrollar y cumplir, basados en los principios fundamentales de la Constitución y facilitar así su cumplimiento, tales como, autonomía, solidaridad eficacia integración.

Por tanto, para que el modelo autonómico descentralizado logre su fundamento y funcione en España, no solo es precisa la cesión de transferencias a las Administraciones Regionales, sino que deben consolidarse los medios de colaboración entre los distintos entes autonómicos y lograr que se cumplan o se hagan cumplir en su totalidad.

Cierto es que el Estado es el que cede sus competencias, que debe facilitar la comunicación en aras del entendimiento y la cultura común y que ha de ser el único encargado de habilitar o facilitar los medios necesarios 
de colaboración, ya que dispone del poder pleno para realizarlo. Pero, para mejorar la coordinación entre el Estado español y sus Comunidades Autónomas, debe hacerse una vinculación entre lo que representa una coordinación obligatoria y lo que se refiere a competencias de un marcado carácter facultativo. La coordinación obligatoria, de tipo formal, no debe impedir que también se refiera a elementos materiales, atribuyéndole el poder a alguna instancia, órgano o entidad de tipo central. Así, por lógica, el Estado ejercerá su competencia en materia de coordinación, pero de forma directa, o bien, indirectamente, por cesión competencial.

La coordinación se establece también de mutuo acuerdo entre las partes, fijado de forma bilateral, con la voluntad de ambas partes y no solo unilateralmente, con la voluntad de las dos partes. Exceptuando que la coordinación ha de ser de carácter obligatorio, el resto de las situaciones es de aplicación libre por las partes, ejercida también siempre de común acuerdo.

En cuanto al procedimiento más empleado, el de los Convenios interterritoriales, en la Constitución no se ha previsto de forma expresa la celebración de convenios entre el Estado central y las Comunidades Autónomas. Ese silencio no quiere decir que estén prohibidos, sino que por alguna razón de tipo material o formal, no se incluyó en el texto.

Evidentemente, las Comunidades Autónomas tienen capacidad para realizar convenios y acuerdos en sus relaciones con otras Comunidades, produciéndose ya algunos problemas para efectuarlos, al crearse tantos regímenes jurídicos como Comunidades Autónomas hay y, por tanto, diferentes ma- neras de entender la prestación de servicios. Así pues, se goza de capacidad contractual tanto para el propio Estado como para las Comunidades Autónomas. Pero esa capacidad contractual adquirida no quiere decir que no disponga de límite alguno, porque sí que hay ciertas restricciones respecto al objeto de convenio, siempre respetando la colaboración necesaria y suficiente y el auxilio de un deber recíproco, no siempre propicio a percepciones positivas.

Se reconoce también la existencia de órganos de cooperación distintos de las Conferencias Sectoriales, como los acuerdos no normativos de cooperación, denominación empleada por Remiro Brotón, reconocido internacionalista español; como cuando se habla de la creación de un Plan y Programa conjunto, estableciéndose cuáles son los sujetos que podrán celebrar convenios de colaboración entre sí y en el marco de sus respectivas competencias.

Por tanto, la Constitución no ha previsto de forma expresa que se puedan celebrar convenios entre el Estado y entre las distintas Comunidades Autónomas, pero el silencio legislativo en este asunto no tiene que ser interpretado de forma negativa, sino que, simplemente, el texto constitucional está carente de una especificación de la materia.

\section{Conclusiones}

Desde aspectos procedimentales o legislativos, puede resolverse la desigualdad tributaria entre ciudadanos que residen en distintas regiones, creados en un sistema político que pretendía precisamente lo contrario. Las relaciones del Estado con las Comunidades Autónomas, lógicamente no 
previstas en detalle en la Constitución, pueden resolverse sin modificarla. Basta con recuperar el consenso que la hizo posible y desarrollar norma de mayor rango a cualquier decreto que regule los procedimientos, sin obviar los principios básicos de la Constitución de 1978 que hicieron a todos los españoles iguales ante la Ley.

\section{Referencias}

\section{Referencias doctrinales}

Bassols Coma, M. (1979). Las relaciones entre la administración periférica del estado y las comunidades autónomas. Revista de Administración Pública. pp 61-78.

Alberti Rovira, E. (1985). Las relaciones de colaboración entre el Estado y las Comunidades Autónomas. Revista Española de Derecho Constitucional Año 5. Núm. 14. Mayo-agosto 1985. p.138.

Cámara Villar, G. (2004). El principio y las relaciones de colaboración entre el Estado y las Comunidades Autónomas. Revista de Derecho Constitucional Europeo. Núm. 1. Enero-Junio de 2004, 197-240.

Barrio García, G. (2000). Principio de Relación entre las Administraciones Públicas. Universidad de la Coruña. p. 67-82.

Roca, M.J. (1996). La neutralidad del Estado: Fundamento doctrinal y actual delimitación en la jurisprudencia. Revista Española de Derecho Constitucional. p. 272 y ss.

Clavero B., Salvador (1985). El acceso a la autonomía de los territorios históricos: Las Comunidades forales. Revista de Estudios Políticos. p. 94 y ss.

González García, I. (2016). El papel de la norma en la colaboración interterritorial: Propuestas de reforma. Revista d'estudis autonòmics i federals. núm. 23, abril 2016, pp. 160-200.

Arrieta Martínez de Pisón, J. (2015) Prohibición de discriminación: la igualdad en materia tributaria y su aplicación efectiva. Revista Mexicana de Derecho Financiero y Tributario. Volumen I, número 4, juliodiciembre 2015 pp. 19-41.
Trujillo, G. (1991) La función consultiva en las Comunidades Autónomas: sus órganos específicos y sus relaciones con el Consejo de Estado. p.158 y ss.

Fernández, Tomas-Ramón (1979). El sistema de distribución de competencias entre el estado y las comunidades autónomas. Revista de Estudios de la vida local. Núm. 201.p. 24 y ss. “

González García, Ignacio (2009). Un distingo constitucionalmente relevante: Convenios de colaboración vs. Acuerdo de cooperación entre comunidades autónomas. Revista de estudios políticos. p 97 y ss.

García Morales, María Jesús (2009). La colaboración a examen. Retos y riesgos de las relaciones intergubernamentales en el estado autonómico. Revista Española de Derecho Constitucional, núm. 86, pp. 65-117.

Romero Sánchez-Cutillas, M. Carmen (2015). Las competencias de las comunidades autónomas en cooperación al desarrollo: Su ejercicio por la Generalitat de Valencia. Tesis doctoral Universidad de Valencia. p 240 y ss.

\section{Referencias normativas}

Constitución Española de 22 de diciembre de 1978. En su art. 143 determina los entes territoriales que pueden ejercer el derecho a la autonomía reconocido en el art. 2 y regula los requisitos para acordar la iniciativa del proceso autonómico. El art. 151.1 prevé un procedimiento especial de acceso a la autonomía, en virtud del cual se podía obtener, inicialmente, un mayor nivel de autogobierno, cumpliendo con unos requisitos más gravosos que los establecidos en el procedimiento común, regulado en el art. 143.

\section{Referencias jurisprudenciales}

Sentencia 13/1992, de 13 de febrero del Tribunal Constitucional. p 957: “... el poder de gasto del Estado o de autorización presupuestaria, manifestación del ejercicio de la potestad legislativa atribuida a las Cortes Generales (art. 66.2. ${ }^{\circ}$ y $134 \mathrm{CE}$ ) no se define por conexión con el reparto competencial de materias que la Constitución establece (art. 148 y $149 \mathrm{CE}$ ), al contrario de lo que acontece con la autonomía financiera de las Comunidades Autónomas, que se vincula al desarrollo y ejecución de las competencias que, de acuerdo con la Constitución, le atribuyen los respectivos Estatutos y las Leyes (art. 156.1. ${ }^{\circ} \mathrm{CE}$ y art. 1.1 ${ }^{\circ}$ 
LOFCA). Por consiguiente, el Estado siempre podrá, en uso de su soberanía financiera, asignar fondos públicos a unas finalidades u otras, pues existen otros preceptos constitucionales (y singularmente los del Capítulo III del Título I) que legitiman la capacidad del Estado para disponer de su Presupuesto en la acción social o económica".
Sentencia del Tribunal Supremo 3006/2018; Sentencia del Tribunal Supremo 2943/2018.

Fecha de recepción: 31 de mayo de 2019

Fecha de aprobación par 1: 14 de agosto de 2019 Fecha de aprobación par 2: 15 de agosto de 2019 